\title{
RELAÇÕES APOSENTADORIA, FAMÍLIA E SAÚDE DO TRABALHADOR
}

\section{Débora Aparecida Moura Campos ${ }^{1}$ Marluce Auxiliadora Borges Glaus Leão ${ }^{2}$}

Resumo: Ao se aposentar, o indivíduo deixa de desempenhar seu papel de trabalhador "formal", passando a focalizar o desempenho de um membro mais ativo na família. Este artigo teve por objetivo identificar as inter-relações entre o fenômeno da aposentadoria na família e na saúde do trabalhador, analisando as publicações nacionais, em especial, artigos científicos, no período de 2013 a 2015, a partir dos descritores "aposentadoria e família", "aposentadoria e saúde do trabalhador". Encontrou-se o total de 198 publicações, sendo 19 delas analisadas. Constatou-se a aposentadoria como um evento de vida e, a coincidência de sua ocorrência com a proximidade da velhice, além da estreita relação com as questões de saúde e de família, configurando-se um desafio durante o processo de envelhecimento. Concluiu-se que a inter-relação dos temas aposentadoria, envelhecimento, contexto familiar e a saúde do trabalhador estão em evidência nas publicações encontradas neste estudo.

Palavras-chave: Aposentadoria; Família; Saúde do trabalhador.

\footnotetext{
1 Aluna do Mestrado Interdisciplinar em Desenvolvimento Humano: formação, políticas e práticas sociais do Programa de Pós-graduação / Universidade de Taubaté, Brasil. E-mail: deboracampos46@gmail.com.

2 Docente do Mestrado Interdisciplinar em Desenvolvimento Humano: formação, políticas e práticas sociais do Programa de Pós-graduação / Universidade de Taubaté, Brasil. E-mail: mgleao08@gmail.com.
} 